\title{
Associations of the $e N O S$ G894T gene polymorphism with target organ damage in children with newly diagnosed primary hypertension
}

\author{
Joanna Śladowska-Kozlowska ${ }^{1}$ • Mieczyslaw Litwin ${ }^{1}$ Anna Niemirska ${ }^{1}$. \\ Aldona Wierzbicka ${ }^{2} \cdot$ Marta Roszczynko $^{3} \cdot$ Malgorzata Szperl $^{3}$
}

Received: 25 April 2015 /Revised: 17 June 2015 / Accepted: 29 June 2015 /Published online: 1 August 2015

(C) The Author(s) 2015. This article is published with open access at Springerlink.com

\begin{abstract}
Background The endothelial nitric oxide synthase (eNOS) G894T gene polymorphism is associated with the risk of primary hypertension $(\mathrm{PH})$ and vascular complications in adults with $\mathrm{PH}$. Methods We explored the associations of the G894T polymorphism with 24-h ambulatory blood pressure, left ventricular mass (LVM), carotid intima media thickness (cIMT), urinary albumin excretion, oxidative stress and inflammatory parameters in 126 children with newly diagnosed $\mathrm{PH}$ and in 83 healthy children.

Results Among the 126 children with PH 92 (73\%) had ambulatory hypertension and $34(27 \%)$ had severe ambulatory hypertension. Left ventricular hypertrophy (LVH) was detected in $39(31 \%)$ patients, cIMT of $>2$ standard deviation scores in $21(16.6 \%)$ patients, albuminuria of $>30 \mathrm{mg} / 24 \mathrm{~h}$ in 18 $(14.3 \%)$ patients and metabolic syndrome (MS) in 22 $(17.5 \%)$ patients. The frequency of the T allele was $52.4 \%$ in the PH group and $54.2 \%$ in the control group (not significant), and in both groups the frequency of the $\mathrm{T}$ allele was consistent with the Hardy-Weinberg equilibrium. Compared with $\mathrm{G}$ allele carriers, hypertensive $\mathrm{T}$ allele carriers had increased cIMT $(p<0.05)$ and more severe albuminuria (not significant, $p=0.1$ ); there was no difference between the groups in hypertension severity and LVM. T and G allele
\end{abstract}

Mieczysław Litwin

m.litwin@ipczd.pl

1 Department of Nephrology and Arterial Hypertension, The Children's Memorial Health Institute, Warsaw, Poland

2 Department of Biochemistry and Experimental Medicine, The Children's Memorial Health Institute, Warsaw, Poland

3 Department of Molecular Biology, Institute of Cardiology, Warsaw, Poland distribution did not differ between patients with and without metabolic syndrome. No significant correlations between the assessed parameters and the eNOS G894T gene polymorphism were found in the controls, although $\mathrm{T}$ allele carriers tended to have an increased cIMT $(p=0.09)$.

Conclusion The eNOS T allele is not more prevalent among hypertensive children than among healthy ones, but it is associated with early vascular damage in children with $\mathrm{PH}$, independent of metabolic abnormalities. No associations between the eNOS G894T polymorphism and metabolic abnormalities were found.

Keywords Primary hypertension · Children · Intima media thickness · eNOS G894T gene polymorphism · Target organ damage $\cdot$ Nitric oxide

\section{Introduction}

Subclinical target organ damage (TOD) in the form of left ventricular hypertrophy (LVH) and/or increased carotid intima-media thickness (cIMT) is already present in 30 $40 \%$ of children with primary hypertension $(\mathrm{PH})$ at the diagnosis of elevated blood pressure (BP) [1-5]. Several complex mechanisms have been hypothesized to play a key role in the development of vascular complications, including metabolic and inflammatory processes, as well specific genetic predisposition. Some data indicate the involvement of endothelial nitric oxide synthase (eNOS) in the development of PH and the association of a relative or absolute decrease of eNOS activity with various vascular complications in response to hemodynamic workload [6]. Other data indicate that relative or absolute defects in the production of nitric oxide (NO) by eNOS or an abundant degradation of NO by enhanced oxidative stress (reactive oxygen species) is associated with various 
vascular complications in response to hemodynamic workload $[6,7]$. In addition, impaired NO bioavailability can also be related to a cellular defect in skeletal muscle tissue, where NO regulates many metabolic and contractile processes, such as basal glucose transport [8].

Several polymorphisms of the eNOS gene have been identified, including a single nucleotide polymorphism (SNP) in the promoter region $\left({ }^{-789} \mathrm{C}\right)$, a variable tandem repeat in intron 4 and a Glu298Asp SNP in intron 7. A glutamic acid to aspartic acid substitution at amino acid position 298 is caused by Guanine (G) to thymine (T) transversion at nucleotide 894 of exon 7 [9]. The eNOS $894 \mathrm{~T}$ variant has lower activity and has been found to associate with coronary heart disease, carotid atherosclerosis and endothelial dysfunction [10-17]. This variant is also associated with enhanced vasoconstrictive response to phenylephrine, hypertensive response to endurance training and development of hypertension $[13,18,19]$. However, it seems that both distribution and clinical relevance of the eNOS G894T polymorphism vary among different ethnic groups [20,21].

To date, the relationship between the eNOS G894T gene polymorphism and vascular complications in hypertensive children has not been investigated. The main intermediate phenotype of children with PH includes metabolic abnormalities typical of metabolic syndrome, oxidative stress and immune activation. These abnormalities are strictly associated with TOD [22-25]. Although there are a few pediatric studies analyzing associations between $e N O S$ polymorphisms and hypertension, obesity and metabolic syndrome, we are not aware of any pediatric study analyzing the associations of eNOS polymorphisms with hypertensive TOD in children with $\mathrm{PH}$ [26-28]. Thus, the aim of our study was to explore associations of the eNOS G894T gene polymorphism with TOD markers, oxidative stress and metabolic and inflammatory parameters in an ethnically homogenous group of 126 children with newly diagnosed PH and in 83 healthy children.

\section{Patients and methods}

\section{Patients}

White, Caucasian children and adolescents admitted consecutively to the The Children's Memorial Health Institute during the period 2005-2008 for investigation of suspected arterial hypertension who had not been previously treated with antihypertensive drugs and in whom $\mathrm{PH}$ was ultimately diagnosed were eligible for entry into the study. Of these 200 children, 126 (median age 15 years, age range $5-18$ years; 31 girls, 95 boys) with untreated $\mathrm{PH}$ who completed all investigative procedures were recruited to the study. PH was diagnosed after a thorough clinical and laboratory diagnostic work-up according to recently published recommendations [29]. In all patients the diagnosis was confirmed by 24 -h ambulatory blood pressure measurement (ABPM). Recordings lasting at least $20 \mathrm{~h}$ with at least $80 \%$ of records available for analysis were considered to be valid. BP values were calculated from the $\mathrm{ABPM}$ as the mean 24-h systolic BP (SBP/24 h) and diastolic $\mathrm{BP}(\mathrm{DBP} / 24 \mathrm{~h})$ and presented as absolute values and as the SBP and DBP indices (SBPi and DBPi, respectively) calculated as the ratio of SBP or DBP to the 95th percentile for age and gender based on the pediatric ABPM reference data [30]. The recently published classification system based on ABPM was used to classify patients as having normal blood pressure, ambulatory hypertension and severe ambulatory hypertension [31]. The exclusion criteria were: diagnosis of secondary hypertension, previous use of antihypertensive drugs, presence of any significant chronic disease (except for $\mathrm{PH}$ ) and acute disease, including infections, in the 6 weeks immediately preceding enrollment. Patients with incomplete biochemical data were also excluded.

\section{Controls}

The control group consisted of 83 Caucasian healthy, normotensive children with a median age 12 (range 5-18) years (43 girls, 40 boys), recruited voluntarily from schools. None of these children had any significant chronic or acute disease, including infections, within the 6 weeks immediately preceding enrollment.

\section{Molecular studies}

EDTA-anticoagulated venous blood samples were collected from all participating children. DNA was extracted from blood leukocytes using the phenol method. Polymorphism of eNOS G894T gene was evaluated by restriction fragment length polymorphism (RFLP) PCR.

\section{Anthropometrics and biochemical assays}

All patients and controls underwent the following assessments, unless indicated otherwise, which included anthropometrical measurements, such as body mass index (BMI), waist circumference (WC) (patients only) and waistto-hip ratio (WHR) (patients only). Obesity and overweight was diagnosed according to the International Obesity Task Force (IOTF) recommendations [32]. In all patients and controls, serum glucose and insulin, blood lipids, serum homocysteine, serum uric acid and C-reactive protein [highsensivity C-reactive protein (hsCRP)], serum asymmetric dimethyloarginine (ADMA) levels, oxidative stress [thiobarbituric acid reactive substances (TBARS) and oxidized lowdensity lipoprotein cholesterol (oxyLDL) concentration] and anti-oxidative defense [reduced glutathione (GSH) concentration and glutathione peroxidase (GPx) activity] were measured. Because some of our patients were under 10 years of 
age, metabolic syndrome (MS) was diagnosed when at least three criteria were fulfilled [BMI $\geq 95$ th percentile for age and gender; arterial hypertension; serum triglycerides $>110 \mathrm{mg} / \mathrm{dl}$; fasting plasma glucose $>100 \mathrm{mg} / \mathrm{dl}$ or $>140 \mathrm{mg} / \mathrm{dl}$ at $2 \mathrm{~h}$ of oral glucose tolerance test; high-density lipoprotein (HDL) cholesterol $<40 \mathrm{mg} / \mathrm{dl}]$ [22].

\section{cIMT measurements}

The cIMT was measured both in controls and PH patients by ultrasound according to methodology described previously [3]. The median and standard deviation (SD) of normal values for cIMT were obtained from normative data published elsewhere [33].

\section{Echocardiography}

Echocardiography (ECHO) was performed in all patients, but due to organizational problems ECHO was not performed in controls. All ECHO examinations were performed by one examiner blinded to the severity of $\mathrm{PH}$ and effectiveness of treatment. ECHO measurements were performed according to the American Society of Echocardiography guidelines and to standardize the left ventricular mass to height ratio, the left ventricular mass index (LVMi) was calculated according to the de Simone formula [34]. LVH was defined as an LVMi value of $>95$ th percentile for age and gender, based on the pediatric LVMi reference data [35].

\section{Laboratory investigations}

Blood samples were taken after $12 \mathrm{~h}$ of fasting and immediately sent to the laboratory. Plasma glucose level was measured by a Siemens Dimension chemistry analyzer (Siemens Medical Solutions, Malvern, PA) . Plasma insulin concentrations and glycated hemoglobin (HbAlc) were measured by radioimmunoassay. An oral glucose tolerance test was carried out in all patients after oral ingestion of $1 \mathrm{~g} / \mathrm{kg}$ body weight (maximum $75 \mathrm{~g}$ ) of glucose. Insulin resistance, as described previously, was expressed as homeostasis model assessment for insulin resistance (HOMA-IR) and as the total triglycerydes:HDL-cholesterol (TTG/HDL) ratio.

The CRP concentration (hsCRP) was determined using highly sensitive immunoturbidimetry (Orion Diagnostica, Espoo, Finland). Lipids and uric acid (UA) concentrations were determined with standard laboratory procedures. Plasma lipid peroxides were determined with the spectrofluorometric method of Yagi and expressed as TBARS. GSH concentration and GPX activity were used as indicators of antioxidant status and were measured spectrophotometrically in erythrocytes (Oxis Bioxytech GSH-420 and GPx-340 assays, respectively; Oxis International Inc., Foster City, CA). OxyLDL and ADMA concentrations were measured by enzyme-linked immunosorbent assay (ELISA) using a commercially available kit. Urinary albumin excretion in 24-h samples was determined by the immunonephelometric method.

The laboratory procedures have been described in detail in a previous study [23].

\section{Statistics}

Because the analyzed groups included subjects of different age and gender, BMI, WC and cIMT values were expressed both as absolute values and as standard deviation scores (SDS) for age and gender. LVM values (in grams) were standardized to height in meters ${ }^{2.7}$. Homogeneity of variance was checked with the Levene test. Continuous variables with a normal distribution were compared by the Student $t$ test for independent variables and expressed as the mean and SD. Continuous values with a non-normal distribution were compared by the Mann-Whitney $U$ test and expressed as the median and range. Comparison between groups was evaluated by the analysis of variance (ANOVA) test with Bonferroni correction. Dichotomous variables were compared using the Chisquare test. Molecular predictors of TOD were assessed in a stepwise regression analysis. The dependent variables were absolute, and standardized values of cIMT and variables which correlated with TOD or differentiated patients with or without TOD were chosen as independent variables. Statistical analysis was done using SPSS12.0PL software (IBM Corp., Armonk, NY).

Calculations to determine whether observed genotype frequencies were consistent with the Hardy-Weinberg equilibrium, which means that in a population in the absence of disturbing factors they will remain constant from one generation to the next, were performed with the Court online calculator (http://www.tufts.edu/ mcourt01/Documents/Court\% 201 ab $\% 20-\% 20$ HW\%20calculator.xls). $P$ values of $<0.05$ were regarded as statistically significant, and those ranging between 0.05 and 0.1 were regarded as a statistical tendency.

\section{Results}

\section{Clinical and biochemical phenotype}

Children with PH had significantly greater BMI, higher serum UA, hsCRP, homocysteine, lipoprotein a, TTG/HDL ratio, plasma insulin, HOMA-IR, ADMA and oxyLDL and lower GPx activity and GSH concentration than normotensive children. They also had significantly greater cIMT values than healthy children. Children with PH had higher triglyceride concentrations and a lower birth weight than normotensive children, but the difference was non-significant for both parameters (Tables 1, 2). 
Table 1 Demographic, clinical and genetic data in patients with primary hypertension and control group

\begin{tabular}{|c|c|c|c|}
\hline Variable & Control group, $N=83$ ( $n=40$ boys $)$ & PH patient group, $N=126(n=95$ boys $)$ & $p$ \\
\hline Age (years) & $12(5-18)$ & $15(5-18)$ & ns \\
\hline Birth weight (g) & $3520(1960-4400)$ & $3355(1410-5250)$ & 0.06 \\
\hline $\operatorname{BMI}\left(\mathrm{kg} / \mathrm{m}^{2}\right)$ & $19.2 \pm 3.9$ & $24.8 \pm 4.5$ & $<0.001$ \\
\hline BMI SDS & $0.27 \pm 1.13$ & $1.75 \pm 1.7$ & $<0.001$ \\
\hline $\mathrm{WC}(\mathrm{cm})$ & n.a. & $84(53-111)$ & - \\
\hline WC SDS & n.a. & $1.62(-2.03$ to 6.12$)$ & - \\
\hline cIMT (mm) & $0.40(0.31-0.53)$ & $0.43(0.34-0.63)$ & $<0.001$ \\
\hline cIMT SDS & $0.50(-2.27$ to 3.46$)$ & $0.97(-1.37$ to 7.83$)$ & $<0.001$ \\
\hline $\operatorname{LVMi}\left(\mathrm{g} / \mathrm{m}^{2.7}\right)$ & n.a & $35.3(19.1-62.3)$ & - \\
\hline Number of patients with GT and TT alleles & $45(54.2 \%)$ & $66(52.4 \%)$ & ns \\
\hline Number of patients with TT alleles & $8(9.6 \%)$ & $13(10.3 \%)$ & ns \\
\hline
\end{tabular}

Data are presented as the mean \pm standard deviation $(\mathrm{SD})$, as the median with the range in parenthesis or as a number with the percentage in parenthesis, as appropriate

$P H$ Primary hypertension, $B M I$ body mass index, cIMT carotid intima-media thickness, $L V M i$ left ventricular mass index, $S D S$ standard deviation score, n.a. not assessed, GT carriers of G894 and T894 allele, TT T894 homozygotes, $W C$ waist circumference

In the PH group, 92 (73\%) children had ambulatory hypertension and $34(27 \%)$ children had severe ambulatory hypertension. MS was diagnosed in $22(17.5 \%)$ patients and in none of the controls. Also in this patient group, 39 (31\%) children had LVH, 21 (16.6\%) children had cIMT of $>2$ SDS and $18(14.3 \%)$ children had albuminuria of $>30 \mathrm{mg} / 24 \mathrm{~h}$.
We found a significant correlation between the LVMi and all of the assessed anthropometrical parameters [BMI $(r=$ $0.34)$, BMI-SDS $(r=0.38)$, WC $(r=0.39)$, WC-SDS $(r=$ $0.34)$ and WHR $(r=0.37)]$. The cIMT-SDS correlated with $\mathrm{SBP} / 24 \mathrm{~h}(r=0.19, p<0.05)$, hsCRP $(r=0.25, p<0.05)$, $\operatorname{GPx}(r=0.23, p<0.05)$ and albuminuria $(R=0.21$, $p<0.05)$. Positive correlations were found between the

Table 2 Laboratory data for patients with primary hypertension and the control group

\begin{tabular}{llll}
\hline Variable & Contro group $(N=83)$ & PH patient group $(N=126)$ & $p$ \\
\hline Cholesterol $(\mathrm{mg} / \mathrm{dl})$ & $175.6 \pm 39.1$ & $173.6 \pm 33.7$ & $\mathrm{~ns}$ \\
Triglicerydes $(\mathrm{mg} / \mathrm{dl})$ & $69(38-312)$ & $84(28-425)$ & 0.05 \\
HDL-cholesterol $(\mathrm{mg} / \mathrm{dl})$ & $46.6 \pm 9.8$ & $44.6 \pm 9.6$ & $\mathrm{~ns}$ \\
TTG/HDL & $1.48(0.64-15)$ & $1.84(0.58-42)$ & $110(43-226)$ \\
LDL-cholesterol $(\mathrm{mg} / \mathrm{dl})$ & $111(60-185)$ & $15.5 \pm 11.7$ & $\mathrm{~ns}$ \\
Lp(a) $(\mathrm{mg} / \mathrm{dl})$ & $11.7 \pm 7.6$ & $5.48 \pm 1.19$ & 0.02 \\
Uric acid $(\mathrm{mg} / \mathrm{l})$ & $4.08 \pm 0.63$ & $10.2 \pm 3.5$ & $0.74(0.02-4.68)$ \\
Homocysteine $(\mu \mathrm{mol} / \mathrm{l})$ & $8.9 \pm 3.4$ & $85(67-109)$ & 0.02 \\
hsCRP $(\mathrm{mg} / \mathrm{dl})$ & $0.44(0.12-6.74)$ & $12.8(3-39)$ & 0.01 \\
Fasting glucose $(\mathrm{mg} / \mathrm{dl})$ & $90(78-105)$ & $2.78(1.11-8.77)$ & 0.001 \\
Fasting insulin $(\mathrm{mU} / \mathrm{ml})$ & $9(3.3-15)$ & $31.5(23.8-39.9)$ & 0.001 \\
HOMA-IR & $1.9(0.74-3.28)$ & $760.1(441.7-889.4)$ & 0.001 \\
GPx $(\mathrm{U} / \mathrm{gHb})$ & $32.8(20.1-42.1)$ & $0.55(0.25-1.45)$ & 0.005 \\
GSH $(\mu \mathrm{mol} / \mathrm{l})$ & $792.5(253.2-889.1)$ & $400.15(45.8-1372)$ \\
ADMA $(\mu \mathrm{mol} / \mathrm{l})$ & $0.46(0.15-1.30)$ & $14.7(2-270)$ & 0.001 \\
oxyLDL $(\mathrm{mU} / \mathrm{ml})$ & $260.9(0.21-1272)$ & 0.02 \\
Albuminuria $(\mathrm{mg} / 24 \mathrm{~h})$ & n.a. & 0.008 \\
\hline
\end{tabular}

Data are presented as the mean $\pm \mathrm{SD}$ or as the median with the range in parenthesis, as appropriate

$H D L$ high-density lipoprotein-cholesterol, $T T G$ total triglycerydes, $L D L$ low-density lipoprotein-cholesterol, $L p(a)$ lipoprotiein a, $h s C R P$ high-sensivity C-reactive protein, HOMA-IR homeostasis model assessment for insulin resistance, GPx glutathione peroxidase, GSH reduced glutathione, $A D M A$ serum asymmetric dimethyloarginine, $o x y L D L$ oxidized LDL-cholesterol, $n s$ not significant 
LVMi and values of albuminuria and hsCRP $(R=0.22$, $p<0.05)$ and a negative correlation was found with birth weight $(R=-0.27, p<0.05)$.

Compared to hypertensive children with a cIMT of $<2$ SDS, hypertensive children with cIMT of $>2$ SDS presented significantly higher values of SBP/24 h (134 \pm 9 vs. $128 \pm$ $8 \mathrm{mmHg} ; p<0.05), \mathrm{SBPi} / 24 \mathrm{~h}(1.05 \pm 0.07$ vs. $1.01 \pm 0.06$; $p<0.05)$ and albuminuria [24.2 (4.7-270) vs. $13.3[2-172]$ $\mathrm{mg} / 24 \mathrm{~h} ; p<0.05$ ].

In the control group, cIMT-SDS trended to correlate with hsCRP $(R=0.21, p=0.06)$ and fasting glucose $(R=0.24, p=$ $0.07)$. No significant differences between controls with a cIMT of $>2$ SDS (12 patients, $14.5 \%$ ) and those with a cIMT of $<2$ SDS (71 patients , $85.5 \%$ ) were found.

\section{Molecular studies—baseline comparisons}

The frequency of the Tallele was $52.4 \%$ in the PH group and $54.2 \%$ in the control group [not significant (n.s.)], and in both groups observed genotype frequencies were consistent with the Hardy-Weinberg equilibrium ( $\mathrm{PH}: \mathrm{chi}^{2}=0.06, p=0.798$, controls: $\mathrm{chi}^{2}=0.054, p=0.8159$ ).

Hypertensive T allele carriers had greater cIMT, cIMT-SDS (both significant at $p<0.05$ ) and albuminuria (n.s. at $p=0.1$ ) than $\mathrm{G}$ allele carriers but did not differ in relation to hypertension severity and LVMi (Table 3). No significant correlations between the assessed parameters of oxidative stress and anti-oxidative defense and eNOS G894T gene polymorphism were found. $T$ and $G$ allele distribution did not differ between patients with and without MS [TT frequency: $3(13.6 \%)$ patients vs. 10 (9.6\%) patients, respectively; GG: 10 (45.5\%) patients vs. 50 (48.1\%) patients, respectively; not significant].

In comparison to GG homozygotes, TT homozygotes with PH had higher cIMT [0.465 (0.36-0.57) vs. $0.43(0.34-0.52)$ $\mathrm{mm} ; p=0.02]$, cIMT-SDS [1.49 ( -0.35 to 2.7$)$ vs. $0.86(-1.05$ to 3.12$) ; p=0.03$ ] and a tendency to higher relative wall thickness (RWT) [0.36 (0.28-0.45) vs. $0.32(0.23-0.59) \mathrm{mm} ; p=$ $0.1]$. GG homozygotes had a significantly lower birth weight, higher visceral fat accumulations, higher hsCRP and higher heart rate in ABPM than the other groups (Table 3).

In the control group no significant correlations between assessed parameters and the eNOS G894T gene polymorphism were found. However, T allele carriers tended to have greater cIMT than GG homozygotes [0.41(0.33-0.53) $\mathrm{mm}$ vs. $0.40(0.31-0.48) \mathrm{mm} ; p=0.09)$.

TT homozygotes with PH in comparison to TT homozygotes in the control group presented only significantly higher values of cIMT $(p=0.04)$ and a tendency to higher cIMT SDS $(p=0.07)$ (Table 4).

Stepwise regression analysis revealed that the main predictors of increased cIMT-SDS $\left(R^{2}=0.23, F=1.8\right)$ were the G894T gene polymorphism (beta $=0.342, p=0.01$ ) and GPx activity (beta $=0.288, p=0.047$ ). For absolute cIMT values $\left(R^{2}=0.22, F=1.97\right)$ the main predictors were also G894T gene polymorphism (beta $=0.343, p=0.01$ ) and GPx activity (beta $=$ $0.28, p=0.049$ ).

\section{Discussion}

The main finding of our study is that the T894 allele of the eNOS gene is associated with early vascular damage in children with PH independently of metabolic abnormalities. This association was not found in normotensive children.

Reports showing an association between the G894T polymorphism, vascular complications and hypertension in humans are not consistent $[10-17,36]$. The meta-analysis of Niu and Qi indicated that the T894 allele may be associated with an increased risk of hypertension. However, this association exhibited no significance in white people, suggesting the heterogeneous associations of G894T polymorphism in specific populations (Asian populations) [21]. Similarly, interethnic differences in the distribution of eNOS genetic variants have been described in various studies, including comparisons of black and white Brazilians and of Caucasians, AfroAmericans and Asians [20,37]. Thus, our findings may be limited only to a population of Caucasian children.

In our homogenous group of Caucasian children the frequency of the Tallele was $52.4 \%$ in the PH group and 54.2\% in the control group; this slight difference between the groups was not significant. Also, we did not find any differences in BP levels or prevalence of MS between the analyzed genotypes. These results are similar to those of Miranda at al. who did not find any association between the G894T polymorphism and MS in obese children and adolescents [28]. However, these authors indicated that the CC genotype for the T786C polymorphism of eNOS is associated with MS [28].

In our study, hypertensive $\mathrm{T}$ allele carriers had greater cIMT and tended to have greater albuminuria that the $\mathrm{G}$ allele carriers (Table 3). Moreover, in comparison to the GG homozygotes, the TT homozygotes presented with higher birth weight, lower visceral fat accumulation, lower hsCRP and lower heart rate in ABPM, a significantly higher cIMT and a tendency to greater RWT. Similarly, in the control group, T allele carriers tended to have greater cIMT. The correlation between $\mathrm{T}$ allele frequency and intima-media thickening has also been found in some groups of adult patients [14-16]. Some authors have reported that the 894 T allele of the eNOS polymorphism is also associated with carotid atheroma and with the presence, extent and severity of angiographically assessed coronary artery disease $[12,13]$. Czarnecka et al. found higher cIMT values in both hypertensive $\mathrm{T}$ allele carriers and among $\mathrm{T}$ allele carrier offspring of hypertensive patients [15]. Our finding of an association between the $894 \mathrm{~T}$ allele and greater cIMT only in hypertensive children suggests 
Table 3 Demographic, clinical and laboratory data in patients with primary hypertension according to eNOS G894T genotype variants

\begin{tabular}{|c|c|c|c|c|c|}
\hline Variables & GG (1) & $\mathrm{GT}+\mathrm{TT}(2)$ & GT (2a) & TT (2b) & $p$ \\
\hline$N$ & 60 & 66 & 53 & 13 & \\
\hline Birth weight (g) & $3325(1790-4200)$ & $3400(1410-5250)$ & $3300(1410-4000)$ & $3500(3140-5250)$ & $\begin{array}{l}1 \text { vs. } 2 \mathrm{~b} p=0.03 \\
2 \mathrm{a} \text { vs. } 2 \mathrm{~b} p=0.06\end{array}$ \\
\hline BMI & $24.9 \pm 4.4$ & $24.8 \pm 4.6$ & $24.6 \pm 4.2$ & $25.6 \pm 6.3$ & ns \\
\hline BMI-SDS & $1.55(-1.26$ to 6.03$)$ & $1.64(-0.81$ to 9.69$)$ & $1.64(-1.56$ to 9.69$)$ & $1.79(-0.81$ to 5.8$)$ & ns \\
\hline WC (cm) & $85.14 \pm 10.8$ & $81.23 \pm 12.9$ & $81.23 \pm 12.08$ & $81.33 \pm 16.6$ & ns \\
\hline WC-SDS & $1.82(-0.94$ to 4.88$)$ & $1.38(-2.03-6.1)$ & $1.35(-2.03-6.12)$ & $1.40(-1.1$ to 4.5$)$ & ns \\
\hline WHR & $0.86 \pm 0.07$ & $0.83 \pm 0.06$ & $0.82 \pm 0.07$ & $0.84 \pm 0.07$ & $\begin{array}{l}1 \text { vs. } 2 p=0.01 \\
1 \text { vs. } 2 \text { a } p<0.01\end{array}$ \\
\hline $\mathrm{SPBP} / 24 \mathrm{~h}(\mathrm{mmHg})$ & $129 \pm 8$ & $130 \pm 8$ & $130 \pm 8$ & $130 \pm 9$ & ns \\
\hline $\mathrm{SBPi} / 24 \mathrm{~h}$ & $1.02(0.89-1.17)$ & $1.02(0.91-1.23)$ & $1.02(0.92-1.20)$ & $1.03(0.90-1.23)$ & ns \\
\hline $\mathrm{DBP} / 24 \mathrm{~h}(\mathrm{mmHg})$ & $73 \pm 6$ & $72 \pm 8$ & $72 \pm 7$ & $73 \pm 9$ & ns \\
\hline $\mathrm{DBPi} / 24 \mathrm{~h}$ & $0.95(0.81-1.23)$ & $0.94(0.69-1.27)$ & $0.94(0.82-1.27)$ & $0.94(0.8-1.12)$ & ns \\
\hline $\mathrm{HR} / 24 \mathrm{~h}(/ \mathrm{min})$ & $82 \pm 10$ & $77 \pm 12$ & $77 \pm 12$ & $78 \pm 10$ & $\begin{array}{c}1 \text { vs. } 2 p=0.02 \\
1 \text { vs. } 2 \mathrm{a} p=0.03 \\
1 \text { vs. } 2 \mathrm{~b} p=0.1\end{array}$ \\
\hline IMT (mm) & $0,43(0.34-0.52)$ & $0.44(0.345-0.62)$ & $0.43(0.345-0.62)$ & $0.465(0.36-0.57)$ & $\begin{array}{l}1 \text { vs. } 2 p=0.01 \\
1 \text { vs. } 2 \mathrm{a} p=0.05 \\
1 \text { vs. } 2 \mathrm{~b} p=0.02\end{array}$ \\
\hline IMT-SDS & $0,86(-1.05$ to 3.12$)$ & $1.03(-1.37$ to 7.2$)$ & $1(-1.37-7.2)$ & $1.49(-0.35$ to 2.7$)$ & $\begin{array}{l}1 \text { vs. } 2 p=0.03 \\
1 \text { v.s } 2 \mathrm{a} p=0.06 \\
1 \text { vs } 2 \mathrm{~b} p=0.03\end{array}$ \\
\hline Albuminuria (mg/24 h) & $13.5(2-57.6)$ & $15.2(4.6-250)$ & $14.7(4.6-250)$ & $16.2(9.3-54.6)$ & 1 vs. $2 p=0.17$ \\
\hline $\operatorname{LVMi}\left(\mathrm{g} / \mathrm{m}^{2.7}\right)$ & $35.2 \pm 8.0$ & $36.9 \pm 9.4$ & $36.6 \pm 9.4$ & $37.7 \pm 9.6$ & ns \\
\hline RWT (mm) & $0.32(0.23-0.59)$ & $0.36(0.23-0.59)$ & $0.35(0.23-0.59)$ & $0.36(0.28-0.45)$ & 1 vs. $2 \mathrm{~b} p=0.1$ \\
\hline TTG/HDL & $1.87(0.78--12.9)$ & $1.84(0.58-42.5)$ & $1.9(0.58-42.5)$ & $1.77(0.78-2.91)$ & ns \\
\hline hsCRP (mg/l) & $0.76(0.02-3.98)$ & $0.69(0.05-4.68)$ & $0.84(0.05-4.68)$ & $0.41(0.14-0.82)$ & $\begin{array}{l}1 \text { vs. } 2 \mathrm{~b} p=0.05 \\
2 \mathrm{a} \text { vs. } 2 \mathrm{~b} p=0.06\end{array}$ \\
\hline Fasting insulin (mU/ml) & $12.9(6.4-39)$ & $12.8(3-36)$ & $12.8(3-36)$ & $12.9(6.7-30)$ & ns \\
\hline HOMA -R & $2.86(1.26-8.77)$ & $2.68(1.1-7.9)$ & $2.73(1.1-7.92)$ & $2.64(1.38-6.23)$ & ns \\
\hline $\mathrm{HbA} 1 \mathrm{c}(\%)$ & $5.4(4.1-6.8)$ & $5.3(4.2-6.6)$ & $5.3(4.2-6.6)$ & $5.0(4.5-5-6)$ & $\begin{array}{l}1 \text { vs. } 2 p=0.11 \\
1 \text { vs. } 2 b p=0.1\end{array}$ \\
\hline GPx (U/gHb) & $31.6(28.3-39.9)$ & $31.4(23-8-38.1)$ & $31.3(23.8-38.1)$ & $33.2(30.8-36.9)$ & $2 \mathrm{a}$ vs. $2 \mathrm{~b} p=0.07$ \\
\hline Number of patients with MS & 10 & 12 & 9 & 3 & ns \\
\hline
\end{tabular}

Data are presented as the mean $\pm \mathrm{SD}$, as the median with the range in parenthesis or as a number, as appropriate

GG G894 homozygotes, GT carriers of G894 and T894 allele, TT T894 homozygotes, WHR waist-to-hip ratio, SBP/24 $h$ mean systolic blood pressure in 24-h ambulatory blood pressure monitoring (ABPM), SBPi/24 h index of SBP/24 h, DBP/24 h mean diastolic systolic blood pressure in 24-h ABPM, $D B P i / 24 h$ index of DBP/24 h, HR/24 h mean heart rate in 24-h ABPM, RWT relative wall thickness, HbAlc glycated hemoglobin, $M S$ metabolic syndrome

that genetic polymorphism of the eNOS gene predisposes to arterial injury only when the arterial wall is exposed to higher blood pressure. However, it does not mean that the eNOS gene polymorphism is associated with elevated blood pressure.

Arterial remodeling in HT patients is mainly determined by reduced NO bioavailability. Apart from the significance of the genetically conditioned decreased eNOS release/availability, obesity and inflammation also lead to reduced eNOS bioavailability and consequently to cardiovascular diseases [26, 38, 39].
Jiménez-Morales found that their subjects with the TT genotype displayed a lower vascular response (lower increase in post-ischemic capillary flow) compared with TG and GG genotypes and that this response was improved after an intake of meals rich in high-phenol virgin olive oil [40]. Similarly, Leeson et al. found a positive relationship between n-3 fatty acid level and flow-mediated dilation in $894 \mathrm{~T}$ carriers, but not in G894 homozygotes. Additionally, among men, smoking has been associated with lower flow-mediated dilation in $\mathrm{T}$ allele carriers but not in GG homozygotes [17]. A study of the 
Table 4 Comparison of some clinical and laboratory data of TT allele carriers in the control and primary hypertension group

\begin{tabular}{llll}
\hline Variables & TT controls & TT patients with PH & $p$ \\
\hline Number of pts (\%) & $8(9.6 \%)$ & $13(10.3 \%)$ & $\mathrm{ns}$ \\
BMI $\left(\mathrm{kg} / \mathrm{m}^{2}\right)$ & $20.7 \pm 3.7$ & $25.6 \pm 6.3$ & 0.07 \\
BMI-SD & $0.62 \pm 0.98$ & $1.89 \pm 2.05$ & $\mathrm{~ns}$ \\
cIMT (mm) & $0.41(0.31-0.44)$ & $0.46(0.37-0.57)$ & 0.04 \\
cIMT-SDS & $0.67(-1.58$ to 1.72$)$ & $1.49(-0.35$ to 2.52$)$ & 0.07 \\
hsCRP (mg/l) & $0.24(0.15-0.71)$ & $0.41(0.14-0.82)$ & $\mathrm{ns}$ \\
TTG/HDL & $1.8(1.0-2.9)$ & $1.8(0.8-2.9)$ & $\mathrm{ns}$ \\
Fasting insulin (mU/ml) & $12(7.6-12)$ & $12.9(6.7-30)$ & 0.1 \\
HOMA-IR & $2.42(1.06-2.85)$ & $2.64(1.38-6.23)$ & $\mathrm{ns}$ \\
\hline
\end{tabular}

Data are presented as the mean $\pm \mathrm{SD}$, as the median with the range in parenthesis or as a number with the percentage in parenthesis, as appropriate

$B M I$ body mass index, $c I M T$ carotid intima-media thickness, $h s C R P$ high-sensivity C-reactive protein, TTG/ $H D L$ total triglycerydes/ high density lipoprotein cholesterol, HOMA-IR homeostasis model assessment for insulin resistance functional consequences of the Glu298Asp polymorphism of the eNOS gene in healthy volunteers found that TT allele carriers, i.e. Asp homozygotes, had decreased vasodilatory response to acetylcholine in the forearm, which indicates blunted endothelial-dependent vasodilation [41]. The role of the Glu298Asp polymorphism in the regulation of blood pressure status was recently evaluated in over 2000 children and adolescents participating in the European Youth Heart Study. Asp homozygotes were found to have slightly higher blood pressure values at rest compared to Glu298 carriers. Interestingly, this difference was found only in adolescents (pubertal and post-pubertal subjects), but not in prepubertal children. Moreover, physical activity modified the genetic effect, which was most apparent in inactive subjects [27].

It is suspected that the Glu298Asp polymorphism reduces the degree of interaction of eNOS with caveolin-1 and thereby hinders the localization of eNOS in caveolae and diminishes shear-dependent eNOS activation [16, 42]. However, the molecular mechanism of the effects of different eNOS polymorphisms is not clear. In studies not limited to the analysis of SNPs but which analyzed the effects of different haplotypes of eNOS, such as a SNP in the promoter region $\left(\mathrm{T}^{-789} \mathrm{C}\right)$, a variable tandem repeat in intron 4 and a Glu298Asp SNP in intron 7, subjects who had haplotype "C-4b-Glu" had the lowest plasma and whole blood nitrite levels [43, 44]. Interestingly, there marked inter-ethnic differences in the distribution of different haplotypes have been observed [37]. Souza-Costa at al. compared the distribution of some eNOS haplotypes in normotensive obese/hypertensive obese children with healthy controls and found that only the $\mathrm{CbG}$ haplotype constellation was more frequent in hypertensive obese children in comparison to the other analyzed group [26].

Following these observations, the eNOS modulatory role of statins and virgin olive oil may have an influence on functional regulation of the cardiovascular system and may offer new perspectives for the better use of statins and phenol-rich olive oil in ameliorating cardiovascular disorders, especially in patients with downregulated eNOS function, such as carriers of the TT allele of the G894T polymorphism. Moreover, the interaction between the genetic variation in eNOS and BP may also be modified by physical activity. Physical activity may strengthen the production and effect of $\mathrm{NO}$ in the regulation of $\mathrm{BP}$ through endothelial vasodilatation and could be an effective way of controlling BP in individuals with a genetic predisposition toward hypertension or hypertensive children with subclinical arterial injury [27, 45].

The main limitation of our study was the low number of patients and controls. Because of this, some differences between groups were not statistically significant. It is important to emphasize that some authors have failed to find any relationship between the $894 \mathrm{~T}$ variant and the risk of atherosclerosis $[18,46]$. In the systematic assessment and meta-analyses of candidate gene polymorphisms studied in more than 5000 subjects, including the most extensively studied polymorphisms for cIMT, the apolipoprotein E $\varepsilon 2 / \varepsilon 3 / \varepsilon 4$ polymorphism is the only one to date for which a convincing association with cIMT has been demonstrated [47]. Even if the number of patients included in our study is small, it should be emphasized that all participants were clinically welldefined and selected. Our study is the first to show an association between the eNOS G894T polymorphism and early vascular damage in children with untreated PH. Certainly, we have examined only one selected polymorphism, which provides less verified information. $\mathrm{PH}$ is a complex state that involves many genes apart from the eNOS gene and is not entirely explained by genetic factors. Other risk factors may modify the effects of eNOS polymorphisms on the risk of vascular damage. 
In conclusion, we demonstrate for the first time in children with PH that the G894T polymorphism of the eNOS gene is associated with early vascular damage independent of metabolic abnormalities.

Conflict of interest The authors declare that they have no conflict of interest.

Ethical approval This was a cross-sectional study which adhered to the principles of the Declaration of Helsinki and was approved by the local Ethical Committee.

Informed consent All parents and children aged $>12$ years provided written informed consent.

Open Access This article is distributed under the terms of the Creative Commons Attribution 4.0 International License (http://creativecommons.org/licenses/by/4.0/), which permits unrestricted use, distribution, and reproduction in any medium, provided you give appropriate credit to the original author(s) and the source, provide a link to the Creative Commons license, and indicate if changes were made.

\section{References}

1. Sorof J, Alexandrov A, Garami Z, Turner JL, Grafe RE, Lai D, Portman RJ (2003) Carotid ultrasonography for detection of vascular abnormalities in hypertensive children. Pediatr Nephrol 18: $1020-1024$

2. Hanevold C, Waller J, Daniels S, Portman R, Sorof J (2004) International Pediatric Hypertension Association: the effects of obesity, gender and ethnic group on left ventricular hypertrophy and geometry in hypertensive children: a collaborative study of the International Pediatric Hypertension Association. Pediatrics 113:328-333

3. Litwin M, Niemirska A, Śladowska J, Antoniewicz J, Daszkowska J, Wierzbicka A, Wawer ZT, Grenda R (2006) Left ventricular hypertrophy and arterial wall thickening in children with essential hypertension. Pediatr Nephrol 21:811-819

4. McNiece KL, Gupta-Malhotra M, Samuels J, Bell C, Garcia K, Poffenbarger T, Sorof JM, Portman RJ (2007) Left ventricular hypertrophy in hypertensive adolescents. Analysis of risk by 2004 National High Blood Pressure Education Program Working Group criteria. Hypertension 50:392-395

5. Levy D, Garrison RJ, Savage DD, Kannel WB, Castelli WP (1990) Prognostic implications of echocardiographically determined left ventricular mass in the Framingham Heart Study. N Engl J Med 322:1561-1566

6. Ignarro L, Cirino G, Casini A, Napoli C (1999) Nitric oxide as a signaling molecule in the vascular system: an overview. J Cardiovasc Pharmacol 34:879-886

7. Cai H, Harrison DG (2000) Endothelial dysfunction in cardiovascular diseases. The role of oxidant stress. Circ Res 87:840-844

8. Kapur S, Bedard S, Marcotte B, Cote C, Marette A (1997) Expression of nitric oxide synthase in skeletal muscle: a novel role for nitric oxide as a modulator of insulin action. Diabetes 46:16911700

9. Markus HS, Ruigrok Y, Ali N, Powell JF (1998) Endothelial nitric oxide synthase exon 7 polymorphism, ischemic cerebrovascular disease, and carotid atheroma. Stroke 29:1908-1911
10. Hingorani A, Liang C, Fatibene J, Lyon A, Monteith S, Parsons A, Haydock S, Hopper RV, Stephens NG, O'Shaughnessy KM, Brown MJ (1999) A common variant of the endothelial nitric oxide synthase (Glu298 $\rightarrow$ Asp) is a major risk factor for coronary artery disease in the UK. Circulation 100:1515-1520

11. Hibi K, Ishigami T, Tamura K, Mizushima S, Nyui N, Fujita T, Ochiai H, Kosuge M, Watanabe Y, Yoshii Y, Kihara M, Kimura K, Ishii M, Umemura S (1998) Endothelial nitric oxide synthase gene polymorphism and acute myocardial infarction. Hypertension 32:521-526

12. Colombo MG, Andreassi MG, Paradossi U, Botto N, Manfredi S, Masetti S, Rossi G, Clerico A, Biagini A (2002) Evidence for association of a common variant of the endothelial nitric oxide synthase gene (Glu298 $\rightarrow$ Asp polymorphism) to the presence, extent, and severity of coronary artery disease. Heart 87:525-528

13. Lembo G, De Luca N, Battagli C, Iovino G, Aretini A, Musicco M, Frati G, Pompeo F, Vecchione C, Trimarco B (2001) A common variant of endothelial nitric oxide synthase (Glu298Asp) is an independent risk factor for carotid atherosclerosis. Stroke 32:735-740

14. Wolff B, Braun C, Schlüter C, Grabe HJ, Popowski K, Völzke H, Lüdemann J, John U, Cascorbi I (2005) Endothelial nitric oxide synthase $\mathrm{Glu}(298) \rightarrow$ Asp polymorphism, carotid atherosclerosis and intima-media thickness in a general population sample. Clin Sci (Lond) 109:475-481

15. Czarnecka D, Kawecka-Jaszcz K, Stolarz K, Olszanecka A, Dembińska-Kieć A, Kieć-Wilk B (2005) Ambulatory blood pressure, left ventricular mass and vascular phenotypes in relation to the endothelial nitric oxide synthase gene Glu298Asp and intron 4 polymorphisms in a population-based family study. J Hum Hypertens 19:413-420

16. Testa A, Spoto B, Sanguedolce M, Parlongo R, Pisano A, Tripepi G, Benedetto F, Mallamaci F, Zoccali C (2012) eNOS and caveolin1 gene polymorphisms interaction and intima media thickness: a proof of concept study in ESRD patients. Am J Hypertens 25:103108

17. Leeson C, Hingorani A, Mullen M, Jeerooburkhan N, Kattenhorn M, Cole T, Muller D, Lucas A, Humphries S, Deanfield J (2002) Glu298Asp endothelial nitric oxide synthase gene polymorphism interacts with environmental and dietary factors to influence endothelial function. Circ Res 90:1153-1158

18. Karvonen J, Kauma H, Kervinen K, Rantala M, Ikäheimo M, Päivänsalo M, Savolainen M, Kesäniemi Y (2002) Endothelial nitric oxide synthase gene Glu298Asp polymorphism and blood pressure, left ventricular mass and carotid artery atherosclerosis in a population-based cohort. J Intern Med 251:102-110

19. Neves FJ, Silva BM, Rocha NG, Sales AR, Ribeiro GS, Nóbrega AC (2010) Effect of the $894 \mathrm{G}>\mathrm{T}$ polymorphism of the endothelial nitric oxide synthase on vascular reactivity following maximal dynamic exercise. J Hypertens 28:764-770

20. Marroni A, Metzger I, Souza-Costa D, Nagassaki S, Sandrim V, Correa R, Rios-Santos F, Tanus-Santos J (2005) Consistent interethnic differences in the distribution of clinically relevant endothelial nitric oxide synthase genetic polymorphisms. Nitric Oxide 12: 177-182

21. Niu W, Qi Y (2011) An updated meta-analysis of endothelial nitric oxide synthase gene: three well-characterized polymorphisms with hypertension. PLoS One 6:e24266

22. Litwin M, Śladowska J, Antoniewicz J, Niemirska A, Wierzbicka A, Daszkowska J, Wawer ZT, Janas R, Grenda R (2007) Metabolic abnormalities, insulin resistance and metabolic syndrome in children with primary hypertension. Am J Hypertens 20:875-882

23. Śladowska-Kozłowska J, Litwin M, Niemirska A, Płudowski P, Wierzbicka A, Skorupa E, Wawer Z, Janas R (2012) Oxidative stress in hypertensive children before and after 1 year of antihypertensive therapy. Pediatr Nephrol 27:1943-1951 
24. Litwin M, Michałkiewicz J, Niemirska A, Gackowska L, Kubiszewska I, Wierzbicka A, Wawer Z, Janas R (2010) Inflammatory activation in children with primary hypertension. Pediatr Nephrol 25:1711-1718

25. Litwin M, Michałkiewicz J, Trojanek J, Niemirska A, Wierzbicka A, Szalecki M (2013) Altered genes profile of renin-angiotensin system, immune system, and adipokines receptors in leukocytes of children with primary hypertension. Hypertension 61:431-436

26. Souza-Costa D, Belo V, Silva P, Sertorio J, Metzger I, Lanna C, Machado M, Tanus-Santos J (2011) eNOS haplotype associated with hypertension in obese children and adolescents. Int J Obes (Lond) 35:387-392

27. Grontved A, Andersen L, Franks P, Verhage B, Wareham N, Ekelund U, Loos RJF, Brage S (2011) NOS3 variants, physical activity, and blood pressure in the European Youth Heart Study. Am J Hypertens 24:444-450

28. Miranda J, Belo V, Souza-Costa D, Lanna C, Tanus-Santos J (2013) eNOS polymorphism associated with metabolic syndrome in children and adolescents. Mol Cell Biochem 372:155-160

29. Lurbe E, Cifkova R, Cruickshank JK, Dillon MJ, Ferreira I, Invitti C, Kuznetsova T, Laurent S, Mancia G, Morales-Olivas F, Rascher W, Redon J, Schaefer F, Seeman T, Stergiou G, Wühl E, Zanchetti A, European Society of Hypertension (2009) Management of high blood pressure in children and adolescents: recommendations of the European Society of Hypertension. J Hypertens 27:1719-1742

30. Wühl E, Witte K, Soergel M, Mehls O, Shaefer F, German Working Group on Pediatric Hypertension (2002) Distribution of 24-h ambulatory blood pressure in children: normalized reference values and role of body dimensions. J Hypertens 20:1995-2007

31. Urbina E, Alpert B, Flynn J, Hayman L, Harshfield GA, Jacobson M, Mahoney L, McCrindle B, Mietus-Snyder M, Steinberger J, Daniels S, American Heart Association Atherosclerosis, Hypertension, and Obesity in Youth Committee (2008) Ambulatory Blood Pressure Monitoring in Children and Adolescents Recomendations for Standard Assessment. A Scientific Statement from the American Heart Association Atherosclerosis, Hypertension, and Obesity in Youth Committee of the Council on Cardiovascular Disease in the Young and the Council for High Blood Pressure Research. Hypertension 52:433451

32. Cole T, Bellizzi M, Flegal K, Dietz W (2000) Establishing a standard definition for child overweight and obesity worldwide: international study. BMJ 320:1240-1243

33. Doyon A, Kracht D, Bayazit AK, Deveci M, Duzova A, Krmar R, Litwin M, Niemirska A, Oguz B, Schmidt BM, Sözeri B, Querfeld U, Melk A, Schaefer F, Wühl E, 4C Study Consortium (2013) Carotid artery intima-media thickness and distensibility in children and adolescents: reference values and role of body dimensions. Hypertension 62:550-556

34. de Simone G, Daniels S, Devereux R, Meyer R, Roman M, de Divitiis O, Alderman M (1992) Left ventricular mass and body size in normotensive children and adults: assessment of allometric relations and impact of overweight. J Am Coll Cardiol 20:1251-1260
35. Khoury P, Mitsnefes M, Daniels S, Kimball T (2009) Age-specific reference intervals for indexed left ventricular mass in children. J Am Soc Echocardiogr 22:709-714

36. Bhuiyan A, Chen W, Srinivasan S, Rice J, Mock N, Tang R, Gene Bond M, Boerwinkle E, Berenson G (2008) Interaction of Gprotein beta3 subunit and nitric oxide synthase gene polymorphisms on carotid artery intima-media thickness in young adults: the Bogalusa Heart Study. Am J Hypertens 21:917-921

37. Tanus-Santos J, Desai M, Flockhart D (2001) Effects of ethnicity on the distribution of clinically relevant endothelial nitric oxide variants. Pharmacogenetics 11:719-725

38. Gruber H, Mayer C, Mangge H, Fauler G, Grandits N, WildersTruschnig M (2008) Obesity reduces the bioavailability of nitric oxide in juveniles. Int J Obes (Lond) 32:826-831

39. Yetik-Anacak G, Catravas J (2006) Nitric oxide and the endothelium: history and impact on cardiovascular disease. Vasc Pharmacol 45:268-276

40. Jiménez-Morales A, Ruano J, Delgado-Lista J, Fernandez J, Camargo A, López-Segura F, Villarraso J, Fuentes-Jiménez F, López-Miranda J, Pérez-Jiménez F (2011) NOS3 Glu298Asp polymorphism interacts with virgin olive oil phenols to determine the postprandial endothelial function in patients with the metabolic syndrome. J Clin Endocrinol Metab 96:1694-1702

41. Godfrey V, Chan S-L, Cassidy A, Butle R, Choy A, Fardon T, Struthers A, Lang C (2007) The functional consequence of the Glu298Asp polymorphism of the endothelial nitric oxide synthase gene in young healthy volunteers. Cardiovasc Drug Rev 25:280 288

42. Joshi M, Mineo C, Shaul P, Bauer J (2007) Biochemical consequences of the NOS3 Glu298Asp variation in human endothelium: altered caveolar localization and impaired response to shear. FASEB J 21:2655-2663

43. Metzger I, Sertório J, Tanus-Santos J (2007) Modulation of nitric oxide formation by endothelial nitric oxide synthase gene haplotypes. Free Radic Biol Med 43:987-992

44. Metzger I, Ishizawa M, Rios-Santos F, Carvalho W, Tanus-Santos J (2011) Endothelial nitric oxide synthase gene haplotypes affect nitrite levels in black subjects. Pharmacogenom J 11:393-399

45. de Moraes A, Fernández-Alvira J, Carvalho H, Meirhaeghe A, Dallongeville J, Kafatos A, Marcos A, Molnar D, Manios Y, Ruiz JR, Labayen I, Widhalm K, Breidenassel C, Gonzalez-Gróss M, Moreno L (2014) Physical activity modifies the associations between genetic variants and blood pressure in European adolescents. J Pediatr 165:1046-1049

46. Schneider M, Erdmann J, Delles C, Fleck E, Regitz-Zagrosek V, Schmieder RE (2000) Functional gene testing of the Glu298Asp polymorphism of the endothelial NO synthase. J Hypertens 18: 1767-1773

47. Paternoster L, Martinez-Gonzalez N, Charleton R, Chung M, Lewis S, Sudlow CL (2010) Genetic effects on carotid intima-media thickness: systematic assessment and meta-analyses of candidate gene polymorphisms studied in more than 5000 subjects. Circ Cardiovasc Genet 3:15-21 